\title{
HOMOCYSTEINE: A NEWER AND NOVEL INDEPENDENT RISK FACTOR AND CARDIAC MARKER FOR ACUTE MI
}

\author{
ANOOP KUMAR, PREETI SHARMA*, PRADEEP KUMAR, DR ASHOK KUMAR
}

${ }^{1}$ Department of Biochemistry, Santosh Medical College Hospital, Ghaziabad, Uttar Pradesh, India. ${ }^{2}$ Department of Medicine, Santosh Medical College Hospital, Ghaziabad, Uttar Pradesh, India. Email: prcdri2003@yahoo.co.in

Received: 06 September 2018, Revised and Accepted: 16 November 2018

\section{ABSTRACT}

Objective: The objective of this study was to estimate homocysteine levels in myocardial infarction (MI) patients (troponin-T positive) and normal healthy individuals (troponin-T negative) subsequently to make comparisons with other cardiac markers.

Methods: A cross-sectional study consisting of 172 subjects involving 100 patients of non-diabetic MI and 72 apparently healthy controls with no history of diabetes and/or MI was done between December 2017 and May 2018. The diagnosis of MI was established with electrocardiogram findings and troponin-T estimation. Blood samples were collected and processed for the estimation of homocysteine, troponin-T, creatine kinase MB fraction (CK-MB), and lactate dehydrogenase.

Results: In the present study, a total of 100 troponin-T positive cases and 72 troponin-T negative as controls were studied. The mean age in the cases was $62.15 \pm 7.75$ years and in the controls was $61.49 \pm 8.35$ years $(\mathrm{p}=0.592)$. The mean value of homocysteine in the troponin-T positive group was $30.56 \pm 19.79 \mu \mathrm{mol} / \mathrm{l}$ and in the troponin-T negative group was $10.28 \pm 4.03 \mu \mathrm{mol} / \mathrm{l}(\mathrm{p}<0.0001)$. Homocysteine was deranged in $98 \%$ troponin-T positive group and in only $18.06 \%$ in troponin-T negative group. The difference was statistically significant ( $\mathrm{p}<0.0001)$. No significant correlation was found between homocysteine and CK-MB and LDH in troponin-T positive and negative patients individually.

Conclusion: This study indicated that homocysteine is sensitive cardiac markers for the diagnosis of MI but shows no specific correlation with other cardiac markers and thus it should be predicted independently.

Keywords: Infarction, Homocysteine, Creatine.

(C) 2019 The Authors. Published by Innovare Academic Sciences Pvt Ltd. This is an open access article under the CC BY license (http://creativecommons. org/licenses/by/4. 0/) DOI: http://dx.doi.org/10.22159/ajpcr.2019.v12i3.29559

\section{INTRODUCTION}

Myocardial infarction (MI) or acute coronary syndromes (ACS) remains the major clinical event in patients with atherosclerosis of the coronary arteries [1]. Cardiovascular disease, especially coronary heart disease (CHD), is epidemic in India. According to the Registrar General of India reports, CHD led to $17 \%$ of total deaths and $26 \%$ of adult deaths in $2001-2003$, which increased to $23 \%$ of total and $32 \%$ of adult deaths in 2010-2013 [2]. In the younger age population, the rate of acute MI (AMI) is $5 \%$ [3].

The diagnosis of AMI requires multidimensional approach of physical examination and clinical symptoms assessment, electrocardiogram (ECG) examination, and laboratory marker studies. The effective management should involve the laboratory markers results and risk stratification. Even among patients with ST-segment elevated MI, for whom initial therapeutic options are well defined, patient risk characteristics impact the short and long-term medical decisionmaking [4].

Analysis of cardiac biomarkers has become the front-line diagnostic tools for AMI and has enabled the doctors in the rapid diagnosis and treatment planning, thereby reducing the mortality rate by a great extent. However, the future of cardiac biomarkers will follow the analysis of a panel of markers for the diagnosis and prognosis of MI.

Homocysteine, a newer cardiac marker, is quite promising in this aspect apart from other routinely used markers such as lactate dehydrogenase (LDH), aspartate aminotransferase (AST), creatine kinase MB fraction (CPK-MB), and C-reactive protein (CRP). Since McCully [5] first proposed the homocysteine theory of atherosclerosis, a lot of observational studies have reported a relation between blood levels of homocysteine and CHD [6].

Thus, this observational study was undertaken to see the levels of inflammatory marker. Homocysteine as an independent predictor of coronary artery disease (CAD) and its relationship with other cardiac biomarkers such as CRP, AST, LDH, troponin, and CK-MB to suggest a future panel of cardiac biomarkers for diagnosis of MI.

\section{METHODS}

A cross-sectional study was conducted in the department of biochemistry in a tertiary care hospital. A total of 172 patients were included in this study and were divided into two groups. Group I (Cases) - consisted of 100 diagnosed cases of non-diabetic MI admitted to emergency and intensive care unit of the Santosh Medical College Hospital and RC Ghaziabad. Group II (controls) - consisted of 72 healthy subjects with no history of diabetes and/or MI. Informed consent was obtained from patients. Information extraction forms were used to gather data from patient files.

All patients more than 35 years of age (male and female) of confirmed non-diabetic MI based on ECG findings and cardiac enzymes (troponin-T) were included in the study. Patients with diabetes mellitus having MI, recent history of surgery and trauma within the preceding 2 months, and renal insufficiency (serum creatinine $>1.5 \mathrm{mg} / \mathrm{dl}$ ), patients with cerebrovascular accidents or previous history of cerebrovascular accidents, patients having evidence of infections, inflammatory disease, and malignancy, patient taking drugs such as Vitamin B-complex or folic acid, and hormone replacement therapy, and those who were not willing to participate were excluded from the study. The initial evaluation 
of patients with MI consisted of history, physical examination, ECG changes, and laboratory investigation (troponin-T). The blood samples were taken from all the cases and controls and were immediately analyzed for biochemical parameters.

Under all aseptic precautions, about $5 \mathrm{ml}$ of venous blood samples was collected by clean venepuncture in a sterile plain and ethylenediaminetetraacetic acid vial. Blood samples were allowed to coagulate after which they were centrifuged at $3000 \mathrm{rpm}$ for $5 \mathrm{~min}$ to obtain serum. The separated clear serum was transferred into sterile bottles and used for the enzyme assay. When not used immediately, they were kept at $-20^{\circ} \mathrm{C}$ and later used within 5 days

Measurement of troponin-T was done qualitatively by rapid test kit method manufacturing by Roche Diagnostics International Ltd., CH-6343 Rotkreuz, Switzerland. Measurement of CK-MB and LDH was done by the International Federation of Clinical Chemistry protocol. Commercial kit produced by Transasia Biomedical Ltd. (H.P.) was used. Serum homocysteine level was estimated in serum sample using enzymelinked immunosorbent assay (ELISA). ELISA kit by Qayee-Bio Ltd., China, and ELISA reader of Robonik (India) Pvt., Ltd., were used in this study.

\section{Statistical analysis}

Categorical variables were presented in number and percentage (\%) and continuous variables were presented as mean \pm SD and median. Normality of data was tested by the Kolmogorov-Smirnov test. If normality was rejected, then non-parametric test was used.

Statistical tests were applied as follows:

1. Quantitative variables were compared using independent $t$-test/ Mann-Whitney U-test (when the data sets were not normally distributed) between the two groups.

2. Qualitative variables were correlated using Chi-square test/Fisher's exact test.

3. Spearman rank correlation coefficient was used to measure the association of various parameters with each other.

Table 1: Mean of age distribution

\begin{tabular}{|c|c|c|c|}
\hline Age (in year) & $\begin{array}{l}\text { Troponin-T } \\
\text { negative }^{\mathrm{a}}\end{array}$ & $\begin{array}{l}\text { Troponin-T } \\
\text { positive }^{b}\end{array}$ & p value \\
\hline Mean $\pm S D$ & $61.49 \pm 8.35$ & $62.15 \pm 7.75$ & 0.592 \\
\hline Median (range) & $61.5(39-76)$ & $62(42-76)$ & \\
\hline Interquartile range & $56-68$ & $56.500-68$ & \\
\hline
\end{tabular}

${ }^{a} n=72,{ }^{b} n=100$
4. Univariate logistic regression was used to evaluate significant risk factors for troponin-T positive.

$\mathrm{p}<0.05$ was regarded as statistically significant.

The data were entered into MS Excel spreadsheet and analysis was done using the Statistical Package for the Social Sciences version 21.0.

\section{RESULTS}

In the present study, a total of 100 troponin-T positive cases and 72 troponin-T negative as controls were studied. The mean age of the cases was $62.15 \pm 7.75$ years and in the controls was $61.49 \pm 8.35$ years. The comparison of mean ages of the two groups has been shown in Table 1. In the present study, troponin-T positive group had $29 \%$ of females and $71 \%$ of males, whereas the control group had $29.17 \%$ of females and $70.83 \%$ of males. The gender distribution and comparison have been shown in Table 2.

Homocysteine was deranged in $98 \%$ troponin-T positive group and in only $18.06 \%$ in troponin-T negative group. The comparison has been shown in Table 3. The mean value of homocysteine in the troponin-T positive group was $30.56 \pm 19.79 \mu \mathrm{mol} / \mathrm{l}$ and in the troponin-T negative group was $10.28 \pm 4.03 \mu \mathrm{mol} / \mathrm{l}$. The comparison has been shown in Table 4 .

The mean value of CK-MB and LDH in the troponin-T positive group was $111.94 \pm 29.59 \mathrm{IU} / \mathrm{l}$ and $564.43 \pm 110.99 \mathrm{IU} / \mathrm{l}$, whereas in the troponin-T negative group was $16.36 \pm 3.77 \mathrm{IU} / \mathrm{l}$ and $223.68 \pm 36.23 \mathrm{IU} / \mathrm{l}$, respectively. The comparison has been shown in Table 5 .

On comparing homocysteine with other cardiac markers, no significant correlation was found between homocysteine and CK-MB, LDH, for troponin-T positive patients ( $p>0.05$ ). It has been shown in Table 6 .

On comparing homocysteine with other cardiac markers, no significant correlation was found between homocysteine and CK-MB, LDH, for troponin-T negative patients ( $p>0.05)$. It has been shown in Table 7 .

On performing univariate logistic regression, homocysteine levels were found to be a significant risk factor of troponin-T positive patients $(\mathrm{p}<0.0001)$. With the increase in 0.1 unit in homocysteine, risk of troponin-T positive patients increased by $12.60 \%$. CK-MB and LDH showed a high standard error and thus the regression analysis did not show a correlation (Table 8).

Table 2: Gender distribution

\begin{tabular}{lllll}
\hline Gender distribution & Troponin-T negative $^{\mathrm{a}}$ (\%) & Troponin-T positive $^{\mathrm{b}}$ (\%) & Total $^{\mathrm{c}}(\mathbf{\% )})$ & p value $^{\text {(\%) }}$ \\
\hline Female & $21(29.17)$ & $29(29.00)$ & $50(29.07)$ & 0.981 \\
Male & $51(70.83)$ & $71(71.00)$ & $122(70.93)$ & \\
\hline
\end{tabular}

${ }^{a} \mathrm{n}(\%), \mathrm{n}=72,{ }^{\mathrm{b}} \mathrm{n}(\%), \mathrm{n}=100,{ }^{\mathrm{c}} \mathrm{n}(\%), \mathrm{n}=172$

Table 3: Homocysteine derangement

\begin{tabular}{lllll}
\hline Homocysteine $(\boldsymbol{\mu m o l} / \mathbf{l})$ & Troponin-T negative $^{\mathrm{a}} \mathbf{( \% )}$ & Troponin-T positive $^{\mathrm{b}} \mathbf{( \% )}$ & Total $^{\mathrm{c}}(\mathbf{\%})$ & \multicolumn{1}{c}{$\mathbf{p ~ v a l u e ~}$} \\
\hline Deranged & $13(18.06)$ & $98(98.00)$ & $111(64.53)$ & $<0.0001^{* *}$ \\
Normal & $59(81.94)$ & $2(2.00)$ & $61(35.47)$ & \\
\hline
\end{tabular}

${ }^{a} \mathrm{n}(\%), \mathrm{n}=72,{ }^{\mathrm{b}} \mathrm{n}(\%), \mathrm{n}=100,{ }^{\mathrm{c} n}(\%), \mathrm{n}=172,{ }^{* *} \mathrm{p}<0.01$

Table 4: Mean distribution of homocysteine

\begin{tabular}{lll}
\hline Homocysteine $(\boldsymbol{\mu m o l} / \mathbf{l})$ & Troponin-T negative $^{\mathbf{a}}$ & Troponin-T positive $^{\mathbf{b}}$ \\
\hline Mean \pm SD & $10.28 \pm 4.03$ & $30.56 \pm 19.79$ \\
Median (range) & $9.45(1.7-18.5)$ & $27.6(13.8-207)$ \\
Interquartile range & $6.800-13.500$ & $23.700-31.800$ \\
\hline
\end{tabular}

an $=72$, b $\mathrm{n}=100, * * \mathrm{p}<0.01$ 


\section{DISCUSSION}

The sociodemographic details of the study were similar. The mean age in the cases was $62.15 \pm 7.75$ years and in the controls was $61.49 \pm 8.35$ years. CK-MB, CRP, LDH, and homocysteine values individually showed a significant difference among troponin-T positive and negative patients.

In our study, the mean value of homocysteine in the troponin-T positive group was $30.56 \pm 19.79 \mu \mathrm{mol} / \mathrm{l}$ and in the troponin-T negative group was $10.28 \pm 4.03 \mu \mathrm{mol} / \mathrm{l}$. The difference was statistically significant. Homocysteine was deranged in $98 \%$ troponin- $\mathrm{T}$ positive group and in only $18.06 \%$ in troponin-T negative group. The difference was statistically significant. In other similar studies, the mean value of homocysteine in the cases was $25.89 \pm 6.18 \mu \mathrm{mol} / \mathrm{l}$ [7] and $24.59 \pm 6.14 \mu \mathrm{mol} / \mathrm{l}[8]$ and in the controls was $13.83 \pm 3.51 \mu \mathrm{mol} / \mathrm{l}[7]$ and $13.73 \pm 3.54 \mu \mathrm{mol} / \mathrm{l}[8]$. The difference was statistically significant $(p<0.01)$ as seen in our study. In another study on 100 patients by Prajapati and Panjwani, homocysteine values were $<13$ in $13 \%$ patients and high in $87 \%$ patients. It was more than 50 in $17 \%$ of patients and $13-50$ in $70 \%$ of patients. They also concluded that hyperhomocysteinemia was more common in vegetarians $(78.16 \%)$ as they lack Vitamin B12 in their diet than non-vegetarians (21.83\%) [9]. In another study by Sanoli G et al. (2017) [10], the mean plasma level of homocysteine in patients $(16.88 \pm 10.84 \mu \mathrm{mol} / \mathrm{l})$ was slightly higher than the control group $(14.18 \pm 4.19 \mu \mathrm{mol} / \mathrm{l})$. His findings were contrary to our study as the mean homocysteine values were not significantly different among cases and controls. Their results do not support the hypothesis that CHD is related to elevated serum homocysteine concentration. The results are not conclusive due to the inability to adequately control for potential confounding factors as well as inadequate sample size [10].

On performing univariate logistic regression in our study, homocysteine levels were significant risk factors of troponin-T positive patients and

Table 5: Mean distribution of other cardiac markers

\begin{tabular}{llll}
\hline $\begin{array}{l}\text { Cardiac } \\
\text { markers }\end{array}$ & $\begin{array}{l}\text { Troponin-T } \\
\text { negative }^{\mathbf{a}}\end{array}$ & $\begin{array}{l}\text { Troponin-T } \\
\text { positive }^{\mathbf{b}}\end{array}$ & p value \\
\hline CK-MB (IU/l) & $16.36 \pm 3.77$ & $111.94 \pm 29.59$ & $<0.0001^{* *}$ \\
LDH (IU/l) & $223.68 \pm 36.23$ & $564.43 \pm 110.99$ & \\
\hline
\end{tabular}

${ }^{\mathrm{a}}$ Mean \pm SD, $\mathrm{n}=72,{ }^{\mathrm{b}}$ mean \pm SD, $\mathrm{n}=100,{ }^{* *} \mathrm{p}<0.01$

Table 6: Homocysteine correlation with CK-MB and LDH in troponin-T positive patients

\begin{tabular}{lll}
\hline Cardiac markers & Correlation coefficient & p value \\
\hline CK-MB (IU/l) & 0.002 & 0.982 \\
LDH (IU/l) & -0.075 & 0.457 \\
\hline
\end{tabular}

Table 7: Homocysteine correlation with CK-MB and LDH in troponin-T negative patients

\begin{tabular}{lll}
\hline Cardiac markers & Correlation coefficient & p value \\
\hline CK-MB (IU/l) & -0.184 & 0.122 \\
LDH (IU/l) & -0.099 & 0.410 \\
\hline
\end{tabular}

CK-MB and LDH showed high standard error and thus did not show correlation. In a meta-analysis conducted by Boushey et al., a study conducted by Stampfer et al. and Chamber et al., all showed that homocysteine was an independent, risk factor for CHD, and independent of conventional risk factors [8]. Ashraf [11] showed homocysteine association with troponin-I. An association between homocysteine concentrations and plasma markers of thrombosis activation in patients admitted for ACS was shown in the study by Al-Obaid et al. [12].

All these studies signify the importance of hyperhomocysteinemia as an independent risk factor in AMI, and thus, serum homocysteine should be assessed in all MI patients in collaboration with other cardiac biomarkers such as CK-MB and LDH.

Homocysteine induces atherogenesis by mechanisms such as endothelial injury, platelet activation, smooth muscle proliferation, oxidative modification of low-density lipoproteins (LDL), and endothelial leukocyte interactions as shown in Flowchart 1 [13].

Homocysteine is known to induce atherothrombosis in many ways: Like homocysteine thiolactate, a by-product of oxidation of homocysteine which combines with LDL to form foam cells. LDL-rich foam cells then get embedded in the vascular endothelium and become fatty streak, which is the starting of an atherosclerotic plaque. Homocysteine thiolactate has also been suggested to impair oxidative phosphorylation and enhance proliferation and fibrosis of smooth muscle cells in the vessels [8].

One mechanism is that the homocysteine reduces the concentration of high-density lipoprotein (HDL) cholesterol in plasma by inhibiting the hepatic synthesis of apo A-I, the main HDL apolipoprotein. HDL which is a good cholesterol and maintains the reverse cholesterol transport is decreased and chances of atheroma start increasing. Elevated homocysteine also causes endothelial cell injury which is followed by platelet aggregation and thrombus formation and last atherosclerosis [9].

Homocysteine enhances lipid peroxidation which may decrease the expression of endothelial nitrous oxide (NO) synthase and directly degrade NO. Autoxidation of homocysteine results in oxidation of LDL through generation of the superoxide anion radical. Homocysteine may also reduce the antioxidant status which could injure endothelial cells. Homocysteine stimulates platelet generation of thromboxane A2, which is a vasoconstrictor and proaggregant [8].

Studies on the association of hyperhomocysteinemia with CAD in different populations have yielded different results with some studies providing evidence for an association while others have not. This may be due to ethnic or geographical differences or due to differences in the case selection. As genetic background and nutritional intake vary in different populations, the homocysteine level varies in different ethnic groups and this may be due to the polymorphism seen in the genes encoding enzymes involved in the metabolism of homocysteine [8].

Our study results should be read within the context of several limitations. First, the study design prevents the inference of causal relationships among variables. Our findings of a strong association of serum homocysteine with the cardiac biomarkers and Troponin-T positivity indirectly highlight the significance of levels of serum

Table 8: Univariate logistic regression of troponin-T positive patients

\begin{tabular}{lllllll}
\hline Parameters & B-error & Standard error & p-value & Odds ratio & \multicolumn{2}{c}{$\mathbf{9 5 \% \text { Confidence interval for odds ratio }}$} \\
\cline { 6 - 7 } & & & & & Lower & Upper \\
\hline Age (in year) & 0.010 & 0.019 & 0.590 & 1.011 & 0.973 & 1.050 \\
CK-MB $(\mathrm{IU} / \mathrm{l})$ & 1.032 & 72.093 & 0.989 & 2.806 & 0.000 & $6.51 \mathrm{E}+61$ \\
LDH $(\mathrm{IU} / \mathrm{l})$ & 0.596 & 25.733 & 0.982 & 1.815 & 0.000 & $1.45 \mathrm{E}+22$ \\
Homocysteine $(\mu \mathrm{mol} / \mathrm{l})$ & 0.815 & 0.191 & $<0.0001^{* *}$ & 2.260 & 1.554 & 3.286 \\
\hline
\end{tabular}

**p $<0.01$ 


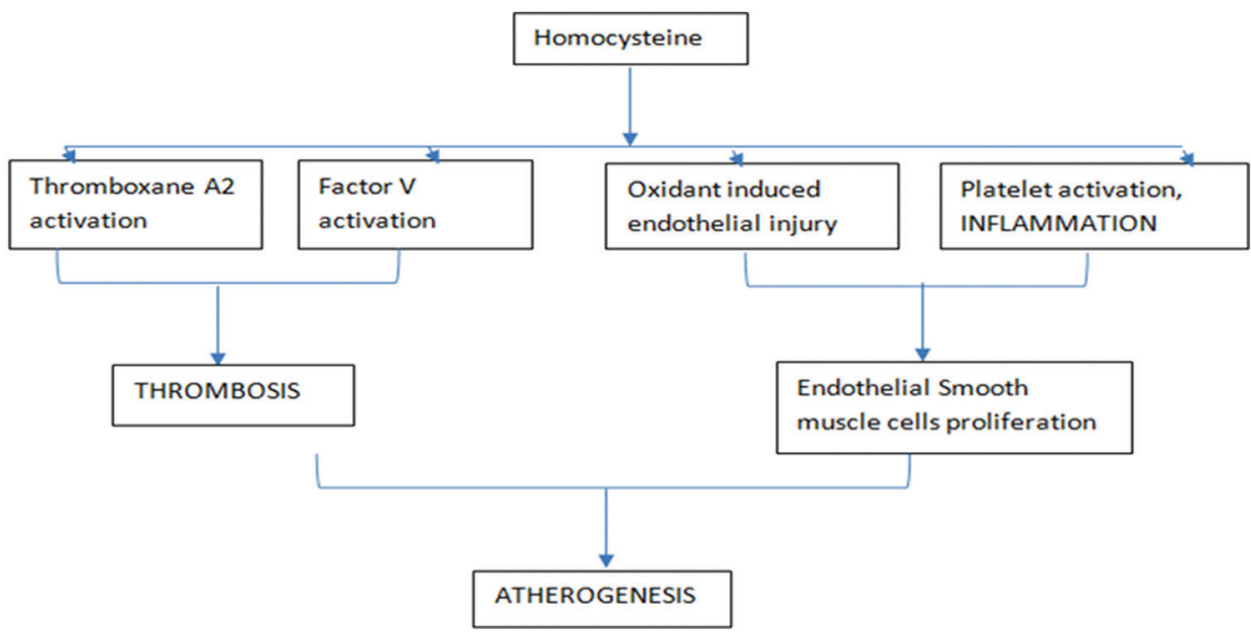

Flowchart 1: Role of homocysteine in atherosclerosis

homocysteine in the extent of myocardial damage and the immediate outcomes of patients with ACS. Finally, it is difficult to determine whether the results of the study would generalize to other ethnicities and geography. Further, research with a larger sample size must be made in major areas to confirm the validity of our results.

\section{CONCLUSION}

Our study indicated that homocysteine, CK-MB, and LDH are sensitive cardiac markers for the diagnosis of MI and can be used as a panel for testing for AMI but show no specific correlation with each other, and thus, they should be used and predicted independently.

\section{ACKNOWLEDGMENT}

We thank Dr. Ketan Garg for assistance in medical writing and editing.

\section{AUTHORS' CONTRIBUTIONS}

$1^{\text {st }}$ Author - Guarantor and data acquisition, from inception till the end of the study. $2^{\text {nd }}$ Author - Concept and design of study, clinical study, and final approval of the version. $3^{\text {rd }}$ Author - Concept and design of study, clinical study, and final approval of the version. $4^{\text {th }}$ Author - Concept and design of study, clinical study, and final approval of the version.

\section{CONFLICTS OF INTEREST}

All authors have none to declare.

\section{REFERENCES}

1. Gupta G, Preeti S, Kumar P, Sharma R. Cardiovascular risk in patients with mild to severe subclinical hypothyroidism. Asian J Pharm Clin Res 2016;9:1-3.
2. Gupta R, Mohan I, Narula J. Trends in coronary heart disease epidemiology in India. Ann Glob Health 2016;82:307-15.

3. Al-Muhtaseb N, Al-Kaissi E, Muhi-eldeen Z, Arafat T, Al-muhtaseb S, Atiyah H. Oxidants and antioxidants as risk factors in young Arabian male patients with acute myocardial infarction. Int J Pharm Pharm Sci 2016;8:273-7.

4. Singh SP, Manda R. A prospective observational study on risk assessment of STEMI patients at a tertiary care hospital. Int J Pharm Pharm Sci 2014;7:148-53.

5. McCully KS. Vascular pathology of homocysteinemia: Implications for the pathogenesis of arteriosclerosis. Am J Pathol 1969;56:111-28.

6. Bozkurt A, Gokel Y, Demir M, Usal A, Cetiner S. Serum total homocysteine and premature coronary heart disease: Prospective study in middle aged patients. Turk J Med Sci 2002;32:53-5.

7. Sorathia P, Pradhan R, Lekharu R. A study of serum homocysteine levels in acute myocardial infarction patients. Int J Curr Res 2014;6:8171-3.

8. Shah H, Haridas N. Evaluation of clinical utility of serum enzymes and troponin- $\mathrm{T}$ in the early stages of acute myocardial infarction. Indian $\mathrm{J}$ Clin Biochem 2003;18:93-101.

9. Prajapati P, Panjwani SJ. Serum homocysteine level as a risk factor for acute coronary syndrome. Int J Adv Sci Eng Technol 2016;19-20.

10. Shanoli G, Sanchita R, Soumitra K, Pritha P, Atreyee D, Ajanta H. Homocysteine-is there any role in coronary heart disease? J Cardiovasc Dis Res 2017;8:46-9.

11. Ashraf MU, Aslam M, Ajmal MR, Habib A. Relationship of serum homocysteine levels with cardiac troponin and ejection fraction in patients admitted with acute coronary syndrome. Int J Adv Pharm Med Bioallied Sci 2015;2:131-5.

12. Al-Obaidi MK, Stubbs PJ, Collinson P, Conroy R, Graham I, Noble MI, et al. Elevated homocysteine levels are associated with increased ischemic myocardial injury in acute coronary syndromes. J Am Coll Cardiol 2000;36:1217-22.

13. Ganguly P, Alam SF. Role of homocysteine in the development of cardiovascular disease. Nutr J 2015;14:6 